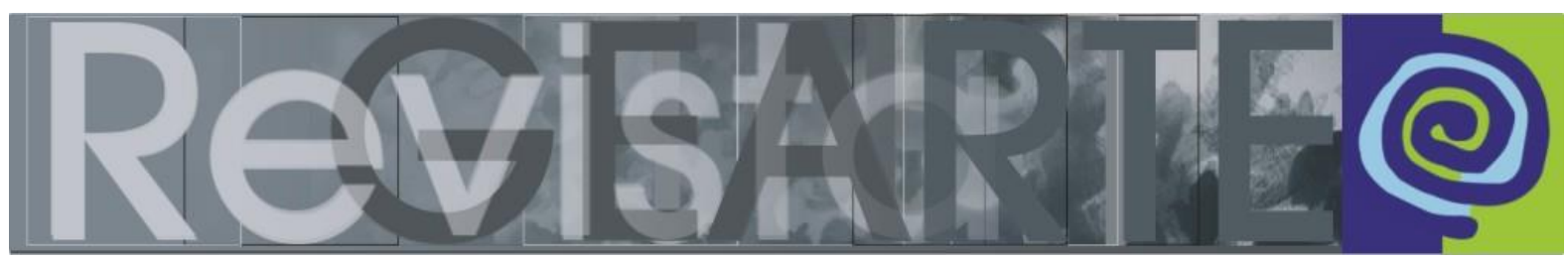

e-ISSN 2357-9854

\title{
Design e Cultura Visual no Ensino de Artes Visuais: diálogos e interações
}

Fazendo parte do eixo temático que tangencia as edições 2017 da revista GEARTE intitulado Tendências contemporâneas do ensino de artes visuais, esse volume tem como conteúdo o Design e a Cultura Visual no Ensino de Artes Visuais, propondo discussões mais amplas acerca desses temas que transitam, de maneira significativa, no universo das artes visuais. Na defesa da interdisciplinaridade, os diálogos e interações advindos do design e da cultura visual caracterizam territórios férteis às experiências contemporâneas que movem o ensino de artes visuais. E é dos estudos e proposições de Barbosa (2008, p. 26) a argumentação de que,

Não basta ensinar arte com horário marcado, é necessário ensinar interdisciplinarmente para provocar a capacidade de estabelecer relações, assim como é recomendável introduzi-la transversalmente em todo o currículo provocando a imbricação de territórios e a multiplicação de interpretações.

Nesse cenário, os elementos de discussão se interrelacionam e se dissolvem, criando ou propondo outras/novas conexões que possibilitam aos arte-educadores incorporar aportes significativos aos seus fazeres e saberes cotidianos. Portanto, essa pretende ser a contribuição do presente número à Revista GEARTE, que aborda aspectos do campo do design e sua diversidade, entendendo que

[...] o design tem se desenvolvido como uma disciplina adaptativa, que age na interface entre o ser humano e o mundo. Propõe-se a resolver problemas ergonômicos, estéticos, representacionais e funcionais dessa relação, podendo ser aplicado nas mais diversas áreas, do design automotivo à sinalização e manipulação da imagem (BUSATO et al., 2010, p. 18).

Essa ideia da presença permanente do design na vida do ser humano é endossada por Bürdek (2010) que aponta ser inimaginável a vida sem ele: "Design pode ser próximo da pele, (como na Moda) ou bem afastado (como no caso do uso espacial). Design não apenas determina nossa existência, mas nesse meio tempo nosso próprio ser" (BÜRDEK, 2010, p. 11). 
E a percepção de totalidade também pode ser compreendida no âmbito da cultura visual, que tem como preocupação "desafiar os limites entre formas visuais novas e tradicionais" (FREEDMAN, 2006, p.42), incluindo as diversas manifestações, não apenas visuais mas as interconexões entre elas e as demais linguagens ou, como sugere Hernández (2010, p. 59) com relação ao ensino da arte para compreensão da cultura visual,

[...] o que se busca é ensinar a estabelecer conexões entre as produções culturais e a compreensão que cada pessoa, dos diferentes grupos (culturais e sociais) elaboram. Se trata, em suma, de ir além do 'que' (o que são as coisas, as experiências, as versões) e começar a perguntar-se os 'porquês' dessas representações, o que as tem feito possíveis, aquilo que mostram e o que excluem, os valores que consagram [...]

A partir das breves considerações apontadas, que procuram fundamentar 0 design e a cultura visual, apresentamos os artigos e ensaios contemplados nessa edição. No primeiro texto, intitulado Creativity in Art Education: Intersecting with Design, Visual Culture, and Social Justice, Flávia Bastos professora e pesquisadora da Universidade de Cincinnati e Enid Zimmermam professora emérita da Universidade de Indiana, Estados Unidos, argumentam e ilustram com exemplos que a pesquisa e a prática na educação artística transcendem a ênfase da expressão de criatividade individual, para uma maior discussão, na qual a criatividade serve como ferramenta para promover abordagens emancipadoras e inclusivas. Examinando duas experiências com alunos de ensino superior, as autoras elucidam como a pesquisa e a pedagogia, num contexto expandido e contemporâneo que inclua design e cultura visual, oferecem conteúdos relevantes para a educação. O conhecimento em arte se transforma diante do contexto de novos ambientes digitais, incluindo diferentes manifestações por meio de imagens, áudios, vídeos e, principalmente, redes sociais e estudos colaborativos. Tais configurações influenciam "novas combinações de pensamento, palavras, ações e imagens". Concluem que através das interações da Arte, design e cultura visual, educadores são capazes de incentivar a justiça social por meio de redes de complacência, suporte e igualdade.

No texto Aprendizagem Colaborativa Online e Educação Artística, de Vitor Silva, da Escola Básica Integrada de Lagoa e Clara Coutinho da Universidade de Minho, Portugal, nos é apresentado um estudo de caso com alunos do ensino fundamental, 
analisando as atividades colaborativas realizadas numa comunidade criada na plataforma digital Edmodo. Na descrição, os pesquisadores relatam que foi aplicada uma variedade de técnicas para desenvolvimento da pesquisa, tais como: diário de bordo, questionários, interações verbais, quiz, tarefa de cariz individual, entrevistas e vídeos tutoriais com objetivo de englobar as diferentes perspectivas dos participantes. A depuração dos dados focou no paradigma interpretativo e qualitativo, recorrendo à análise de conteúdo das discussões e dos artefatos produzidos pelos alunos. Os autores balizam o estudo no fenômeno DIY (Do-lt-Yourself), que refere-se ao ato de criar, produzir, modificar ou reparar algo sem o apoio de profissionais. Os resultados mostram a importância da aprendizagem colaborativa e a influência do emprego de métodos e técnicas no ensino da educação artística no ensino fundamental.

Ana Mae Barbosa, professora e pesquisadora da Universidade Anhembi-Morumbi e Engracia Loureiro Llaberia, doutora em Design pela mesma Universidade, Brasil , no artigo $O$ desenho no design de joias: processos e ensino, abordam os desafios e as conquistas obtidas nos contextos de criação no Design de joias, mais especificamente, os avanços alcançados na contemporaneidade pelo uso do desenho digital que, quando combinado ao desenho gestual à mão, atende a diversos segmentos e modos de produção artesanal e industrial. As autoras problematizam a atividade profissional do designer de joias, uma vez que a terminologia "design" tornou-se palavra da moda, não raras vezes, com conotação superficial e efêmera. Destacam projetos educacionais do início do século XX, propostos por Theodoro Braga, Fidelis Reis e Rui Barbosa, os quais já tinham a compreensão de que o "desenho industrial" deveria ser voltado à aplicação prática. Com os recentes avanços da tecnologia e o crescimento da produção industrial, a profissionalização se tornou necessária. O texto instiga o leitor a pensar o desenho como elemento fundamental de comunicação em design nas diferentes fases dos processos de criação e de produção.

O conteúdo apresentado pelas pesquisadoras Milena Regina Duarte Corrêa e professora Lutiere Dalla Valle da Universidade Federal de Santa Maria, Brasil, no artigo intitulado Arte contemporânea e cultura visual: desdobramentos da naturezamorta no ensino das artes visuais, traz a perspectiva da cultura visual tendo como propósito explorar os contextos visuais e seus desdobramentos no campo das 
imagens originárias da história da arte, mais especificamente aquelas que dizem respeito ao gênero natureza morta. As autoras propõem uma breve retrospectiva histórica sobre a natureza morta e suas interfaces. Na sequência, apresentam questões relacionadas às suas experiências docentes vivenciadas nas escolas da rede pública, nas quais contemplam a multiplicidade de produções e interpretações da natureza morta, da modernidade à contemporaneidade. Ao estabelecer diálogos entre as imagens e a cultura visual, a pretensão é o questionamento, a reflexão e o debate referenciados às problemáticas contemporâneas em torno das imagens, criando contradiscursos, transgredindo ideias enraizadas e propondo diferentes abordagens a essas questões. Discorrem, ainda, acerca das significativas contribuições da cultura visual para explorar a potência subjetiva em torno às contingências históricas e sociais que configuram o olhar.

Em Experimentação audiovisual: considerações sobre a produção de subjetividades na grande mídia, os autores Jéssica Thaís Demarchi, mestranda do Programa de Pós-Graduação em Artes Visuais da Universidade Federal de Pelotas e Cláudio Tarouco de Azevedo, professor e pesquisador da Universidade Federal de Pelotas, Brasil, tecem discussão acerca dos aspectos da produção de subjetividade em contraposição à sobrecarga advinda do consumo visual cotidiano, trazendo conceitos de importantes autores, entre eles Félix Guatarri, referenciado por Nicholas Bourriaud. $O$ que embasa teoricamente a realização da videografia experimental, engendra relações que propiciam o desnudamento de subjetividade desencadeado por meio de uma consciência mais crítica, sensível, solidária e empática. Isso faz borbulhar, nas oficinas propostas, uma tenra produção, salpicada por traços e partículas que se desprendem dos padrões comerciais, problematizando essas estruturas de manipulação mental, tomando assim a criação artística como um instrumento de questionamento, ao instigar outras conexões de sentidos dissonantes dos padrões midiáticos dominantes.

No artigo Fanzines e visualidade, exercícios de autonomia e criação, Ana Basaglia - orientada Ana Mae Barbosa - traz alguns dos seus estudos e experiências com essa arte, que transita entre o design gráfico e a cultura visual. Seu artigo aborda a produção, com alunos, dos fanzines - revistas de caráter autoral, alternativo, independente, sem 
cunho comercial - que permitem ao seu editor misturar preferências pessoais com regras de design. Para ancorar seus estudos, Ana Basaglia busca em Barbosa (2011) alguns aportes, como é o caso da discussão acerca das três principais linhas de cultura visual sendo estudadas a partir do ensino da Arte no Brasil: a cultura visual excludente, a cultura visual includente e a contracultura visual, fazendo uso dessa última em suas reflexões, por apresentar a crítica visual e abominar o discurso verbal. O objeto de estudo explicitado na pesquisa busca investigar as potencialidades da produção de fanzines como meio de expressão da criatividade no espaço escolar, com foco em conceitos de design gráfico, alfabetismo visual, leitura de imagens, autonomia e cultura visual, entrecortados por diálogos em meio às imagens apresentadas. Por fim, a pesquisadora aponta para a necessidade permanente da alfabetização visual e enfatiza a importância dessa produção discente, na qual o design pode ser uma ferramenta essencial, contribuindo para a formação de pessoas reflexivas, críticas, criativas e colaborativas.

Já no texto intitulado Design Reverso: uma nova abordagem para análise e desenvolvimento de artefatos, João Carlos Vela, doutorando do Programa de PósGraduação em Design da Universidade Federal de Santa Catarina, Beatriz Andrielly Nascimento, graduanda do curso de Design de Interiores da Universidade da Região de Joinville e Ricardo Triska, professor e pesquisador da Universidade Federal de Santa Catarina, Brasil, apresentam um breve panorama histórico a partir da década de 1960 até os dias atuais, dos principais processos metodológicos de design. Constatam que, no preceito destes métodos, prevalece um modelo que propõe, a partir de problemas complexos, alcançar soluções simples, o que, no entanto, não muda a estrutura básica de desenvolvimento de produto. Defendem a utilização do Design Reverso como referência para uma nova abordagem. Por que esta técnica seria importante para o Design de produto? Segundo Munari, o processo criativo no design não é absoluto, tão pouco definitivo, coloca-se em constante modificação, na busca de valores que melhorem o processo. Segundo os autores, a abordagem do design reverso consiste em duas etapas de análise: uma generalista e outra estruturada. Ao tratar do Design reverso como uma nova abordagem, o enfoque adotado visa contribuir ou complementar as metodologias usuais. 
Para concluir, as aproximações ao conteúdo "Design e Cultura Visual nas Artes Visuais" propostas por meio dos textos aqui apresentados, possibilitam que pensemos outras formas de abordagem, considerando a diversidade das temáticas e discursos que se colocam, entrelaçadas pelos autores e com os quais pretendemos trilhar esse percurso. Ensejamos que as leituras possam auxiliar nessa caminhada de relações entre os campos do conhecimento aqui propostos. Ótima leitura!

Dra. Marion Divério Faria Pozzi ${ }^{1}$ (Universidade Federal do Rio Grande do Sul — UFRGS, Porto Alegre/RS, Brasil)

Dra. Rita Inês Petrykowski Peixe ${ }^{2}$ (Instituto Federal de Santa Catarina — IFSC, Itajaí/SC, Brasil)

Organizadoras do presente número.

\section{Referências}

BARBOSA, Ana Mae; AMARAL, Lilian (Org.) Interterritorialidade mídias, contextos e educação. São Paulo: Editora Senac; São Paulo: Edições SESC SP, 2008.

BÜRDEK, Bernhard E. Design: história, teoria e prática do design de produtos. São Paulo: Blucher, 2010.

BUSATO, Sérgio Luiz. MARAR, João Fernando. PLÁCIDO DA SILVA, José Carlos. A participação do designer no processo comunicativo: cognição e a codificação estética das mídias. In: PASCHOARELLI, Luis Carlos; MENEZES, Marizilda dos Santos. Design: questões de pesquisa. Rio de Janeiro: Rio Book's, 2010.

FREEDMAN, Kerry. Enseñar la cultura visual: currículum, estética y la vida social del arte. Barcelona: Octaedro, 2006.

HERNÁNDEZ, Fernando. Educación y cultura visual. Barcelona: Octaedro, 2010.

1 Professora Adjunta da Faculdade de Arquitetura da Universidade Federal do Rio Grande do Sul (UFRGS), lotada no Departamento de Design e Expressão Gráfica. Doutorado pelo Programa de Pós-Graduação em Educação PGEDU/UFRGS, mestrado pelo Programa de Pós-Graduação em Arquitetura PROPAR/UFRGS e graduação em Arquitetura e Urbanismo pela Faculdade de Arquitetura FA/UFRGS. Experiência acadêmica nas áreas de Arquitetura, Engenharias, Design Visual e Design de Produto com ênfase em linguagens sincréticas e linguagens gráficas. Experiência em pesquisa no campo da Semiótica Discursiva/ Semiótica Visual com ênfase em linguagens sincréticas e na Habitabilidade das edificações com ênfase em iluminação natural. Chefe do Departamento de Design e Expressão Gráfica da UFRGS. Foi, coordenadora substituta dos cursos de Graduação em Design Visual e Design de Produto da UFRGS. Foi coordenadora adjunto do Programa de Extensão Design no Bairro: atendimento a comunidades carentes. É pesquisadora do Grupo de Pesquisa em Educação e Arte (GEARTE/ UFRGS). E-mail: marionpozzi@gmail.com

2 Possui graduação em Educação Artística-habilitação em artes plásticas e Pedagogia-habilitação em Orientação Educacional; Especialista em arte-educação e Mestre em educação; É doutora em Educação pela Universidade Federal do Rio Grande do Sul (UFRGS/Porto Alegre). Atualmente atua como professora e coordenadora de Extensão no Instituto Federal de Santa Catarina - IFSC, Campus de Itajaí. Pesquisadora do Grupo de Pesquisa em Educação e Arte (GEARTE/UFRGS). Tem experiência em ensino, pesquisa e extensão com ênfase em: métodos e técnicas de ensino, estudos culturais e cultura visual, ensino da arte, formação de professores, design social, economia solidária e artesania. E-mail: ritapeixe@hotmail.com 